\title{
The serotonin receptor 7 and the structural plasticity of brain circuits
}

\section{Floriana Volpicelli ${ }^{1,2}$, Luisa Speranza ${ }^{2}$, Umberto di Porzio ${ }^{2}$, Marianna Crispino ${ }^{*}$ and Carla Perrone-Capano ${ }^{1,2}$}

\author{
${ }^{1}$ Department of Pharmacy, University of Naples Federico II, Naples, Italy \\ 2 Institute of Genetics and Biophysics "Adriano Buzzati Traverso," National Research Council (CNR), Naples, Italy \\ ${ }^{3}$ Department of Biology, University of Naples Federico II, Naples, Italy
}

\section{Edited by:}

Walter Adriani, Istituto Superiore di Sanità, Italy

Reviewed by:

Andrea Fuso, Sapienza University of Rome, Italy

Walter Adriani, Istituto Superiore di Sanità, Italy

Thomas Freret, University of Caen, France

*Correspondence:

Marianna Crispino, Department of

Biology, University of Naples

Federico II, Via Mezzocannone 8,

80134 Naples, Italy

e-mail: crispino@unina.it
Serotonin (5-hydroxytryptamine, 5-HT) modulates numerous physiological processes in the nervous system. Together with its function as neurotransmitter, 5-HT regulates neurite outgrowth, dendritic spine shape and density, growth cone motility and synapse formation during development. In the mammalian brain 5-HT innervation is virtually ubiquitous and the diversity and specificity of its signaling and function arise from at least 20 different receptors, grouped in 7 classes. Here we will focus on the role 5-HT7 receptor (5-HT7R) in the correct establishment of neuronal cytoarchitecture during development, as also suggested by its involvement in several neurodevelopmental disorders. The emerging picture shows that this receptor is a key player contributing not only to shape brain networks during development but also to remodel neuronal wiring in the mature brain, thus controlling cognitive and emotional responses. The activation of 5-HT7R might be one of the mechanisms underlying the ability of the CNS to respond to different stimuli by modulation of its circuit configuration.

Keywords: 5-HT7R, brain connectivity, brain development, neurodevelopmental diseases, neuronal cytoarchitecture, serotonin

\section{SEROTONIN AND BRAIN DEVELOPMENT}

Serotonin is a neurotransmitter modulating numerous physiological processes in the nervous system such as sleep, mood, aggressive behavior, sexual behavior, sensory processing, cognitive control, emotion regulation, autonomic responses, and motor activity (for reviews see Daubert and Condron, 2010; Lesch and Waider, 2012). 5-HT was first discovered in the gut and enterochromaffin cells by the pharmacologist V. Erspamer in the middle thirties and subsequently in blood serum as a vasoconstrictor, hence the name serotonin (serum that gives tone; Rapport et al., 1948).

Serotonergic neurons are found in a variety of organisms, from C. Elegans to vertebrates. In mammals, they are among the earliest neurons being differentiated during development, and comprise a widely distributed neuronal network in the brain (Lesch and Waider, 2012).

Several experimental data have indicated that 5-HT may act as a signaling cue in the fetal brain during critical periods of development. It is recognized that 5 -HT is synthesized early in embryonic development and its receptors are early expressed. In addition to the endogenous 5-HT, the brain of the fetus receives it also from the placenta of the mother, further emphasizing the importance of 5-HT in the early embryonic development of the brain. The contribution of these maternal-placental-fetal interactions appears to be critical for brain circuit wiring and for long-term brain functions (Bonnin et al., 2011). In particular, the 5 -HT system plays a crucial role in the establishment of cortical circuits by controlling key cellular processes including neuronal migration and dendritic differentiation (Puig and Gulledge, 2011; Vitalis et al., 2013; Dayer, 2014). Cortical circuits control cognitive processes and their function is highly dependent on their structure that is shaped during development. Along this line, alteration of the 5-HT signaling system is associated to neurodevelopmental disorders affecting cognitive abilities, as mentioned below. Studies using genetic mouse models reveal that excessive 5-HT levels in the brain alter the correct development of mouse somatosensory cortex (Cases et al., 1996; Persico et al., 2001; Dayer, 2014). On the other hand, the depletion of 5-HT in the brain leads to behavioral and functional deficits, despite the lack of detectable cellular or morphological alterations in the CNS (Hendricks et al., 2003; Savelieva et al., 2008; Alenina et al., 2009). The absence of CNS evident morphological defects in these mouse models suggests that the lack of brain 5-HT may only affect fine shaping of specific circuits, so that these alterations are not revealed by gross morphological analyses of brain. On the other hand, transgenic mice with a 75\% reduction in brain 5-HT levels showed reduced brain growth and delayed cortical maturation during postnatal life (Narboux-Nême et al., 2013). Interestingly, in a recent elegant experiment it was demonstrated that lack of brain 5-HT produced a striking reduction of serotonergic innervation in diencephalic areas (the suprachiasmatic and thalamic paraventricular nuclei) and a marked serotonergic hyperinnervation in forebrain areas (nucleus accumbens and hippocampus; Migliarini et al., 2013). These data strongly suggest that 5-HT can either promote or 
inhibit terminal arborization of serotonergic axons depending on specific targets in the brain. In addition, these findings confirm that alterations of 5-HT levels during CNS development produce severe abnormalities in the serotonergic circuitry affecting the proper wiring of the brain. Consistently, numerous studies from both vertebrate and invertebrate organisms support the idea that 5-HT regulates neurite outgrowth and establishment of neuronal connectivity during brain development (Daubert and Condron, 2010; Lesch and Waider, 2012), and that alterations in early serotonin signaling may produce long-lasting changes. The latter might be the basis of a number of neuropsychiatric disorders which likely have developmental origins, such as schizophrenia, depression, affective disorders, anxiety and autism (Lesch and Waider, 2012; Velasquez et al., 2013; Dayer, 2014). Nevertheless, the key molecular and cellular events through which the 5-HT signaling affects brain connectivity are still poorly investigated. The high number of the 5-HT receptors and the lack of selective pharmacological agonists or inhibitors for the various subtypes have hampered a detailed analysis on their selective involvement in shaping brain networks and modulating neuronal cytoarchitecture. Actually, as mentioned, in the mammalian brain serotonergic neurons exert their effects through 20 subtypes of receptors that are grouped in 7 distinct classes based on pharmacological properties, amino acid sequences, gene organization, and their coupled second messenger pathways. All 5-HT receptors, with the exception of the 5-HT3, are typical Gprotein-coupled-receptors (GPCRs) with seven transmembrane domains. The 5-HT3 receptor, instead, is a ligand-gated ion channel. This great diversity of receptors indicates the wide physiological role of 5-HT in the nervous system, whose complexity still needs to be elucidated (Pytliak et al., 2011; Gellynck et al., 2013).

\section{THE SEROTONIN RECEPTOR 7}

The 5-HT7 receptor was cloned independently by three laboratories in 1993 (Bard et al., 1993; Lovenberg et al., 1993; Ruat et al., 1993). A number of functional splice variants of this receptor have been identified due to the presence of introns in the 5-HT7R gene (Gellynck et al., 2013).

The 5-HT7R activates $\mathrm{G} \alpha_{\mathrm{s}}$ that stimulates adenylate cyclase, resulting in an increase in cAMP. The cAMP activates protein kinase A (PKA) leading to phosphorylation of different proteins (Leopoldo et al., 2011). The 5-HT7R is also coupled to stimulation of the mitogen-activated protein kinase extracellular signal-regulated kinases (ERK; Errico et al., 2001). More recently, the 5-HT7R has also been shown to interact with another member of the $G$ protein family, the $G \alpha_{12}$. Activation of the 5 -HT7R/G $\alpha_{12}$ signaling pathway leads to stimulation of Rho GTPases, Cdc42 and RhoA (Kvachnina et al., 2005; Figure 1).

The 5-HT7R is expressed in both the CNS and in peripheral tissues. In the CNS the receptor is expressed in the diencephalon, forebrain and in the Purkinje neurons of the cerebellum (for reviews see Matthys et al., 2011; Gellynck et al., 2013). The wide distribution of 5-HT7R in the brain reflects the numerous functions in which this receptor is implicated, such as circadian rhythms, sleep-wake cycle, thermoregulation (Leopoldo et al.,

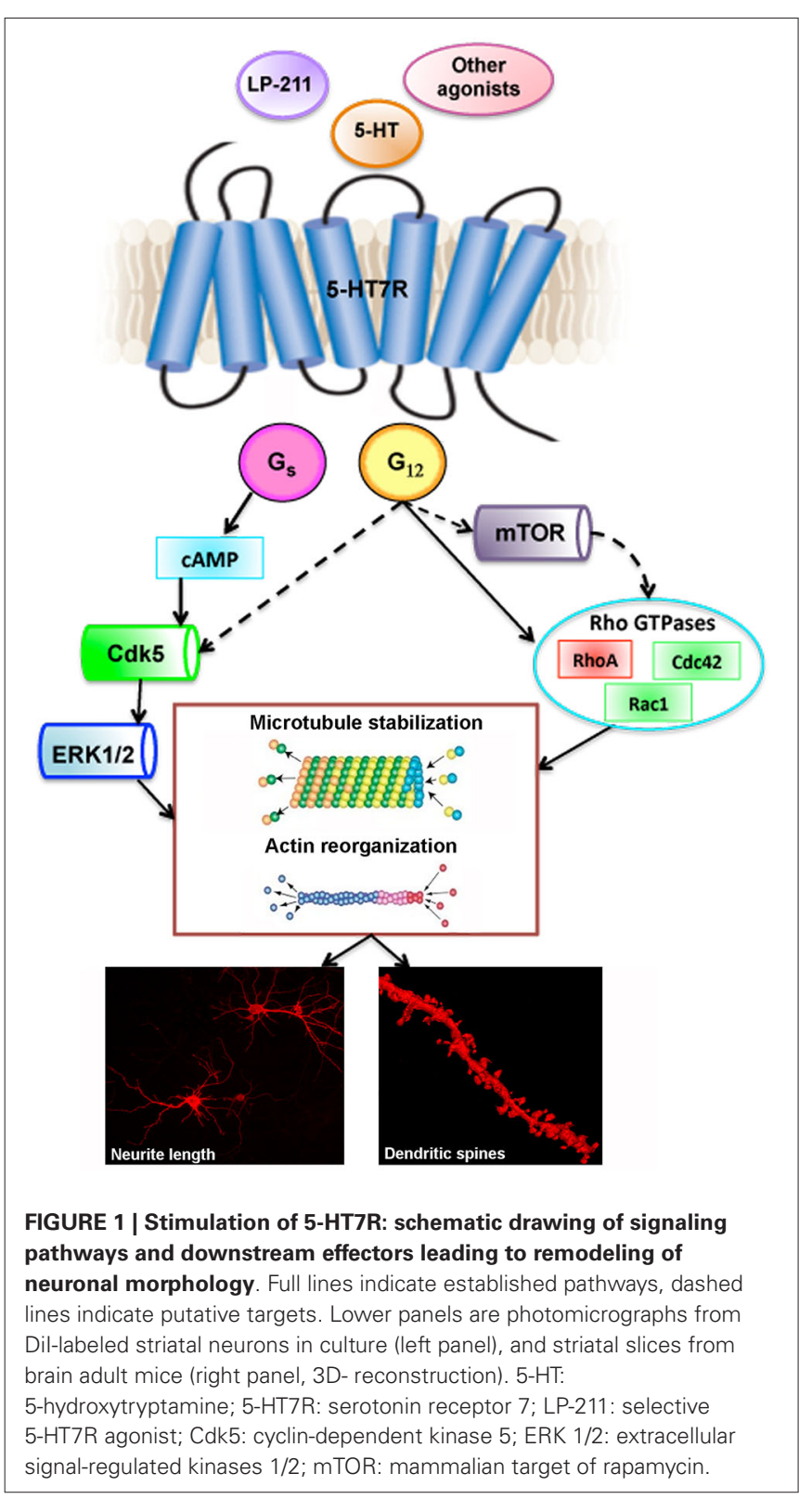

2011; Adriani et al., 2012; Monti et al., 2014; Romano et al., 2014) and nociception (Garcia et al., 2011), but also cognitive functions such as learning and memory processing (Roberts and Hedlund, 2012; Freret et al., 2014; Meneses, 2014). Importantly, the putative involvement of 5-HT7R in many neuropathological processes such as anxiety, schizophrenia, epilepsy, migraine, impulsivity and depression, cognitive and mood disturbances (Hedlund, 2009; Cates et al., 2013; Gellynck et al., 2013), makes it a potential target for new therapeutic applications.

To explain the fact that a single receptor is involved in such a variety of physio-pathological processes of the CNS, the GPCR dimerization has been proposed as a possible key mechanism that introduces diversity in 5-HT7 receptor signaling (Matthys et al., 2011). Accordingly, in a recent study, it has been shown that heterodimerization of 5-HT7 and 5-HT1A receptors differentially 
regulates these receptors signaling and trafficking (Renner et al., 2012).

\section{THE SEROTONIN RECEPTOR 7 SHAPES NEURONAL CIRCUITS DURING DEVELOPMENT}

Numerous recent data indicate that the activation of 5-HT7R modulates neuronal morphology, excitability and plasticity contributing to the establishment of brain connectivity during embryonic and early postnatal life.

Using fibroblast cell lines, it was demonstrated that serotonin stimulation of 5-HT7R induces filopodia formation and cell rounding through interaction of the receptor with $G \alpha_{12}$ subunit of heterotrimeric G-protein and activation of Rho GTPases. This finding prompted more detailed studies using mouse hippocampal neurons in culture, where activation of the endogenous 5HT7R, using the agonist 5-CT, determines pronounced extension of neurite length (Kvachnina et al., 2005). These results have been confirmed by more recent analyses where 5-HT7R was stimulated with $5-\mathrm{HT}$, or with the selective agonist AS19, or with the $5-\mathrm{HT}_{1 \mathrm{~A} / 7}$ receptor agonist 8 -OH-DPAT (Tajiri et al., 2012; Rojas et al., 2014). The effects of the 5-CT, as well as those of the 8-OH-DPAT were abolished by the co-treatment with 5-HT7R selective antagonist SB-269970, indicating the specific involvement of 5-HT7R. The morphogenic effects of the 5-HT7R on neuronal cytoarchitecture have been demonstrated also for neurons from additional CNS areas. Treatment of cultured embryonic neurons from rodent striatal complex and cortex with 8-OH-DPAT and with the highly potent and selective 5-HT7R agonist LP-211, significantly enhances neurite outgrowth through pathways involving Cdk5 and extracellular signal-regulated kinases $1 / 2$ (ERK). These effects are selectively due to the 5-HT7R stimulation since they are blocked by SB269970. Neurite elongation requires de novo protein synthesis and is accompanied by qualitative and quantitative modifications of selected cytoskeletal proteins (Speranza et al., 2013). These findings delineate an overall picture of potential intracellular pathways and molecular mechanisms that underlie modulation of neuronal morphology due to 5-HT7R stimulation (Figure 1).

In accordance with the morphogenic role of 5-HT7R, it was demonstrated that prolonged stimulation of the $5-\mathrm{HT} 7 \mathrm{R} / \mathrm{G} \alpha_{12}$ signaling pathway in early postnatal cultured hippocampal neurons leads to an increased number of dendritic protrusions and synaptic contacts, and enhances spontaneous synaptic activity. A similar morphogenic function of the 5-HT7R was confirmed in organized brain circuitries (organotypic slices preparation from the hippocampus of juvenile mice), where stimulation of 5$\mathrm{HT} 7 \mathrm{R} / \mathrm{G} \alpha_{12}$ signaling pathway potentiates formation of dendritic spines, increases neuronal excitability and modulates synaptic plasticity (LTP). The latter effect was age-dependent, indeed it was observed in 1 week-old mice but not in adult animals, probably due to decreased hippocampal expression of the 5-HT7R during later post-natal stages (Kobe et al., 2012).

Intriguingly, 5-HT7R modulates NMDA receptors activity in hippocampal neurons. Long term activation of the 5-HT7R by the selective agonist LP 12 inhibits glutamate receptor signaling preventing NMDA-induced neurotoxicity (Vasefi et al., 2013a), while acute activation of 5-HT7R promotes NMDA receptor activity (Vasefi et al., 2013b).

In addition, activation of 5-HT7R modulates long-term depression mediated by metabotropic glutamate receptors in wild-type as well as in a mouse model of Fragile $\mathrm{X}$ - syndrome (FXS; Costa et al., 2012). These animals exhibit spatial memory impairment and synapse malfunctioning in the hippocampus, with abnormal enhancement of mGluR-LTD. Abnormal LTD might lead to excessive synapse elimination, whereas physiological LTD is crucial in hippocampal-dependent memory. The activation of 5-HT7R by 5-HT, or 8-OH-DPAT, or LP-211 in hippocampal slices from the FXS mouse model was able to correct excessive mGluR-LTD, bringing it back to its physiological level and thereby restoring synaptic plasticity (Costa et al., 2012). Hippocampal LTP and LTD are the most studied paradigms of synaptic plasticity that cause enduring strengthening and weakening of synapses, paralleled by increase and decrease of dendritic spine volume (Bosch and Hayashi, 2012). These data indicate that brain plasticity is accompanied by modification of neuronal connectivity and formation of new neuronal circuits. The molecular and cellular mechanisms of this modulation are still only partially known, but 5-HT7R seems a good candidate to be involved in the molecular cascade.

\section{THE SEROTONIN RECEPTOR 7 MODULATES CONNECTIVITY IN ADOLESCENT AND MATURE BRAIN}

In addition to the involvement of 5-HT7R in neuronal cytoarchitecture and network construction during embryonic and early postnatal life, 5-HTR7 seems to play a role in the modulation of structural plasticity in adolescent and mature brain circuits. Indeed it is now widely accepted that mature mammalian brain undergoes dramatic structural reorganization with time and experience (Holtmaat and Svoboda, 2009; Sala and Segal, 2014). Intriguingly, it has been demonstrated that brain wiring may be modulated by chronic pharmacological intervention, as indicated by the comprehensive phenotype correction, including dendritic spine density, in adult mice models of FXS treated in young adulthood with a selective mGlu5 inhibitor (Michalon et al., 2012).

In adolescent rodents, it has been hypothesized that 5-HT7R may subserve the persistent structural rearrangements of the brain reward pathways occurring during postnatal development, following chronic methylphenidate exposure (Adriani et al., 2006; Leo et al., 2009). Accordingly, stimulation of 5-HT7R in adolescent rats by intraperitoneal administration of LP-211 $(0.25 \mathrm{mg} / \mathrm{kg} / \mathrm{day}$ for 5 days $)$, induces plastic rearrangements within forebrain networks, accounting for long-lasting behavioral changes in the adulthood (Canese et al., 2014). Similar results were obtained in a rat model for Attention Deficit Hyperactivity Disorder (ADHD) in which prepuberal stimulation of 5-HT7R by intraperitoneal administration of LP-211 (up to $0.5 \mathrm{mg} / \mathrm{kg} / \mathrm{day}$ for 14 days), has long-term effects on adult behavior, improving spatial attention and resulting in modified expression of preand post-synaptic markers (Ruocco et al., 2014a), while the same treatment, during adolescence, modulates the emotional responses (Ruocco et al., 2014b). In addition, stimulation of 5-HT7R exerted consistent effects into exploratory motivation, 
anxiety-related profiles and spontaneous circadian rhythm in adult rodents (Adriani et al., 2012).

Most of these experiments have been performed using LP-211, a novel highly potent and selective 5-HTR7 agonist that, in being brain-penetrant, is particularly useful for in vivo studies (Hedlund et al., 2010). Thus, adult mice treated in vivo with intraperitoneal injection of LP-211 ( $0.25 \mathrm{mg} / \mathrm{kg} /$ day for 3 days $)$ showed a significant increase in the total number and density of dendritic spines in neurons of the dorso-lateral striatum (Speranza et al., in preparation for this issue). In view of the fact that dendritic spines actively participate in the formation of synapses, these data strongly support the notion that this receptor may be involved in shaping the neuronal wiring of the mature CNS.

Along this line, LP-211 stimulation of 5-HT7R by intraperitoneal administration of LP-211 (0.25 mg/kg/day for 7 days $)$ in an adult mouse model of Rett Syndrome (the MeCP2-308 strain) was able to rescue the behavioral deficits and to reverse the abnormal activation of the key molecules regulating actin cytoskeleton dynamics, which in turn modulate neuronal morphology (De Filippis et al., 2014). In addition, inhibition of 5-HT7R with the selective antagonist SB-269970 was able to ameliorate psychomotor and cognitive deficits in animal model of schizophrenia (PACAP-deficient mice), supporting the notion that 5-HT7R is linked to the already mentioned psychiatric disorders such as schizophrenia and depression (Tajiri et al., 2012). This view has been further supported by independent experiments using lurasidone, a novel atypical antipsychotic drug with a powerful antagonist activity for 5-HT7R. Lurasidone ameliorates learning and memory deficits in animal model of schizophrenia and induces an antidepressant-like response in animal models for depression and anxiety. Interestingly, these pharmacological actions of lurasidone are mediated, at least partially, by 5-HT7R (Ishibashi et al., 2010; Cates et al., 2013; Horisawa et al., 2013), corroborating previous data that demonstrate the involvement of 5-HT7R in depression (Hedlund et al., 2005; Mnie-Filali et al., 2007).

The 5-HT7R expression in brain regions involved in learning and memory parallels with its functions. The 5-HT7R knockout mice exhibits specific impairments in contextual learning (Roberts et al., 2004). Several other studies highlight the implication of 5-HT7R in memory and attention-related processes (Gasbarri et al., 2008; Freret et al., 2014; Meneses, 2014), underscoring its role in the modulation of the neuronal network associated with cognitive functions. Therefore, the study of this receptor and its associated intracellular pathways may provide invaluable information for the treatment of learning and memory disorders. From a general point of view, the involvement of 5-HT7R in such numerous neurological disorders associated with abnormal CNS connectivity, recognizes this receptor as a promising target for the development of innovative therapeutical strategies.

\section{CONCLUSION}

Taken together the results highlighted here indicate that 5-HT7R is an important player involved in the establishment of neuronal cytoarchitecture during development of CNS, and strongly suggest its modulatory action in remodeling neuronal morphology and circuitry in the mature brain. Future studies using high resolution in vivo imaging, coupled with the elucidation of molecular mechanisms responsible for morphological modifications will further our knowledge on 5-HT7R role in brain plasticity.

\section{ACKNOWLEDGMENTS}

The work was supported by "Fondo per gli Investimenti di Ricerca di Base" FIRB-RBIN062YH4, and "Medical Research Italy" MERIT-RBNE08LN4P.

\section{REFERENCES}

Adriani, W., Leo, D., Guarino, M., Natoli, A., Di Consiglio, E., De Angelis, G., et al. (2006). Short-term effects of adolescent methylphenidate exposure on brain striatal gene expression and sexual/endocrine parameters in male rats. Ann. N Y Acad. Sci. 1074, 52-73. doi: 10.1196/annals.1369.005

Adriani, W., Travaglini, D., Lacivita, E., Saso, L., Leopoldo, M., and Laviola, G. (2012). Modulatory effects of two novel agonists for serotonin receptor 7 on emotion, motivation and circadian rhythm profiles in mice. Neuropharmacology 62, 833-842. doi: 10.1016/j.neuropharm.2011.09.012

Alenina, N., Kikic, D., Todiras, M., Mosienko, V., Qadri, F., Plehm, R., et al. (2009). Growth retardation and altered autonomic control in mice lacking brain serotonin. Proc. Natl. Acad. Sci. U S A 106, 10332-10337. doi: 10.1073/pnas. 0810793106

Bard, J. A., Zgombick, J., Adham, N., Vaysse, P., Branchek, T. A., and Weinshank, R. L. (1993). Cloning of a novel human serotonin receptor (5-HT7) positively linked to adenylate cyclase. J. Biol. Chem. 268, 23422-23426.

Bonnin, A., Goeden, N., Chen, K., Wilson, M. L., King, J., Shih, J. C., et al. (2011). A transient placental source of serotonin for the fetal forebrain. Nature 472, 347350. doi: 10.1038/nature09972

Bosch, M., and Hayashi, Y. (2012). Structural plasticity of dendritic spines. Curr. Opin. Neurobiol. 22, 383-388. doi: 10.1016/j.conb.2011.09.002

Canese, R., Zoratto, F., Altabella, L., Porcari, P., Mercurio, L., de Pasquale, F., et al. (2014). Persistent modification of forebrain networks and metabolism in rats following adolescent exposure to a 5-HT7 receptor agonist. Psychopharmacology (Berl) doi: 10.1007/s00213-014-3639-6. [Epub ahead of print].

Cases, O., Vitalis, T., Seif, I., De Maeyer, E., Sotelo, C., and Gaspar, P. (1996). Lack of barrels in the somatosensory cortex of monoamine oxidase A-deficient mice: role of a serotonin excess during the critical period. Neuron 16, 297-307. doi: 10. 1016/s0896-6273(00)80048-3

Cates, L. N., Roberts, A. J., Huitron-Resendiz, S., and Hedlund, P. B. (2013). Effects of lurasidone in behavioral models of depression. Role of the $5-\mathrm{HT}_{7}$ receptor subtype. Neuropharmacology 70, 211-217. doi: 10.1016/j.neuropharm.2013.01. 023

Costa, L., Spatuzza, M., D’Antoni, S., Bonaccorso, C. M., Trovato, C., Musumeci, S. A., et al. (2012). Activation of 5-HT7 serotonin receptors reverses metabotropic glutamate receptor-mediated synaptic plasticity in wild-type and Fmr1 knockout mice, a model of Fragile X syndrome. Biol. Psychiatry 72, 924 933. doi: 10.1016/j.biopsych.2012.06.008

Daubert, E. A., and Condron, B. G. (2010). Serotonin: a regulator of neuronal morphology and circuitry. Trends Neurosci. 33, 424-434. doi: 10.1016/j.tins. 2010.05.005

Dayer, A. (2014). Serotonin-related pathways and developmental plasticity: relevance for psychiatric disorders. Dialogues Clin. Neurosci. 16, 29-41.

De Filippis, B., Romano, E., and Laviola, G. (2014). Aberrant Rho GTPases signaling and cognitive dysfunction: in vivo evidence for a compelling molecular relationship. Neurosci. Biobehav. Rev. doi: 10.1016/j.neubiorev.2014.06.007. [Epub ahead of print].

Errico, M., Crozier, R. A., Plummer, M. R., and Cowen, D. S. (2001). 5-HT(7) receptors activate the mitogen activated protein kinase extracellular signal related kinase in cultured rat hippocampal neurons. Neuroscience 102, 361-367. doi: 10.1016/s0306-4522(00)00460-7

Freret, T., Paizanis, E., Beaudet, G., Gusmao-Montaigne, A., Nee, G., Dauphin, F., et al. (2014). Modulation of 5-HT7 receptor: effect on object recognition performances in mice. Psychopharmacology (Berl) 231, 393-400. doi: 10.1007/s00213013-3247-x

Garcia, G. G., Miranda, H. F., Noriega, V., Sierralta, F., Olavarría, L., Zepeda, R. J., et al. (2011). Antinociception induced by atorvastatin in different pain models. Pharmacol. Biochem. Behav. 100, 125-129. doi: 10.1016/j.pbb.2011.08.007 
Gasbarri, A., Cifariello, A., Pompili, A., and Meneses, A. (2008). Effect of 5-HT(7) antagonist SB-269970 in the modulation of working and reference memory in the rat. Behav. Brain Res. 195, 164-170. doi: 10.1016/j.bbr.2007.12.020

Gellynck, E., Heyninck, K., Andressen, K. W., Haegeman, G., Levy, F. O., Vanhoenacker, P., et al. (2013). The serotonin 5-HT7 receptors: two decades of research. Exp. Brain Res. 230, 555-568. doi: 10.1007/s00221-013-3694-y

Hedlund, P. B. (2009). The 5-HT7 receptor and disorders of the nervous system: an overview. Psychopharmacology (Berl) 206, 345-354. doi: 10.1007/s00213-0091626-0

Hedlund, P. B., Huitron-Resendiz, S., Henriksen, S. J., and Sutcliffe, J. G. (2005). 5-HT7 receptor inhibition and inactivation induce antidepressantlike behavior and sleep pattern. Biol. Psychiatry 58, 831-837. doi: 10.1016/j.biopsych.2005. 05.012

Hedlund, P. B., Leopoldo, M., Caccia, S., Sarkisyan, G., Fracasso, C., Martelli, G., et al. (2010). LP-211 is a brain penetrant selective agonist for the serotonin 5-HT(7) receptor. Neurosci. Lett. 481, 12-16. doi: 10.1016/j.neulet.2010. 06.036

Hendricks, T. J., Fyodorov, D. V., Wegman, L. J., Lelutiu, N. B., Pehek, E. A., Yamamoto, B., et al. (2003). Pet-1 ETS gene plays a critical role in 5-HT neuron development and is required for normal anxiety-like and aggressive behavior. Neuron 37, 233-247. doi: 10.1016/s0896-6273(02)01167-4

Holtmaat, A., and Svoboda, K. (2009). Experience-dependent structural synaptic plasticity in the mammalian brain. Nat. Rev. Neurosci. 10, 647-658. doi: 10. 1038/nrn2699

Horisawa, T., Nishikawa, H., Toma, S., Ikeda, A., Horiguchi, M., Ono, M., et al. (2013). The role of 5-HT7 receptor antagonism in the amelioration of MK801-induced learning and memory deficits by the novel atypical antipsychotic drug lurasidone. Behav. Brain Res. 244, 66-69. doi: 10.1016/j.bbr.2013. 01.026

Ishibashi, T., Horisawa, T., Tokuda, K., Ishiyama, T., Ogasa, M., Tagashira, R., et al. (2010). Pharmacological profile of lurasidone, a novel antipsychotic agent with potent 5-hydroxytryptamine 7 (5-HT7) and 5-HT1A receptor activity. J. Pharmacol. Exp. Ther. 334, 171-181. doi: 10.1124/jpet.110.167346

Kobe, F., Guseva, D., Jensen, T. P., Wirth, A., Renner, U., Hess, D., et al. (2012). 5-HT7R/G12 signaling regulates neuronal morphology and function in an agedependent manner. J. Neurosci. 32, 2915-2930. doi: 10.1523/JNEUROSCI.276511.2012

Kvachnina, E., Liu, G., Dityatev, A., Renner, U., Dumuis, A., Richter, D. W., et al. (2005). 5-HT7 receptor is coupled to G alpha subunits of heterotrimeric G12protein to regulate gene transcription and neuronal morphology. J. Neurosci. 25, 7821-7830. doi: 10.1523/jneurosci.1790-05.2005

Leo, D., Adriani, W., Cavaliere, C., Cirillo, G., Marco, E. M., Romano, E., et al. (2009). Methylphenidate to adolescent rats drives enduring changes of accumbal Htr7 expression: implications for impulsive behavior and neuronal morphology. Genes Brain Behav. 8, 356-368. doi: 10.1111/j.1601-183x.2009.00486.x

Leopoldo, M., Lacivita, E., Berardi, F., Perrone, R., and Hedlund, P. B. (2011). Serotonin 5-HT7 receptor agents: structure-activity relationships and potential therapeutic applications in central nervous system disorders. Pharmacol. Ther. 129, 120-148. doi: 10.1016/j.pharmthera.2010.08.013

Lesch, K. P., and Waider, J. (2012). Serotonin in the modulation of neural plasticity and networks: implications for neurodevelopmental disorders. Neuron 76, 175191. doi: 10.1016/j.neuron.2012.09.013

Lovenberg, T. W., Baron, B. M., de Lecea, L., Miller, J. D., Prosser, R. A., Rea, M. A., et al. (1993). A novel adenylyl cyclase-activating serotonin receptor (5-HT7) implicated in the regulation of mammalian circadian rhythms. Neuron 11, 449458. doi: 10.1016/0896-6273(93)90149-1

Matthys, A., Haegeman, G., Van Craenenbroeck, K., and Vanhoenacker, P. (2011). Role of the 5-HT7 receptor in the central nervous system: from current status to future perspectives. Mol. Neurobiol. 43, 228-253. doi: 10.1007/s12035-0118175-3

Meneses, A. (2014). 5-HT7 receptor stimulation and blockade: a therapeutic paradox about memory formation and amnesia. Front. Behav. Neurosci. 8:207. doi: 10.3389/fnbeh.2014.00207

Michalon, A., Sidorov, M., Ballard, T. M., Ozmen, L., Spooren, W., Wettstein, J. G., et al. (2012). Chronic pharmacological mGlu5 inhibition corrects fragile $\mathrm{X}$ in adult mice. Neuron 74, 49-56. doi: 10.1016/j.neuron.2012.03.009

Migliarini, S., Pacini, G., Pelosi, B., Lunardi, G., and Pasqualetti, M. (2013). Lack of brain serotonin affects postnatal development and serotonergic neuronal circuitry formation. Mol. Psychiatry 18, 1106-1118. doi: 10.1038/mp.2012.128
Mnie-Filali, O., Lambás-Señas, L., Zimmer, L., and Haddjeri, N. (2007). 5-HT7 receptor antagonists as a new class of antidepressants. Drug News Perspect. 20, 613-618. doi: 10.1358/dnp.2007.20.10.1181354

Monti, J. M., Leopoldo, M., and Jantos, H. (2014). Systemic administration and local microinjection into the central nervous system of the 5-HT(7) receptor agonist LP-211 modify the sleep-wake cycle in the rat. Behav. Brain Res. 259, 321-329. doi: 10.1016/j.bbr.2013.11.030

Narboux-Nême, N., Angenard, G., Mosienko, V., Klempin, F., Pitychoutis, P. M., Deneris, E., et al. (2013). Postnatal growth defects in mice with constitutive depletion of central serotonin. ACS Chem. Neurosci. 4, 171-181. doi: 10. $1021 / \operatorname{cn} 300165 \mathrm{x}$

Persico, A. M., Mengual, E., Moessner, R., Hall, F. S., Revay, R. S., Sora, I., et al. (2001). Barrel pattern formation requires serotonin uptake by thalamocortical afferents and not vesicular monoamine release. J. Neurosci. 21, 6862-6873.

Puig, M. V., and Gulledge, A. T. (2011). Serotonin and prefrontal cortex function: neurons, networks and circuits. Mol. Neurobiol. 44, 449-464. doi: 10. 1007/s12035-011-8214-0

Pytliak, M., Vargová, V., Mechírová, V., and Felšöci, M. (2011). Serotonin receptors-from molecular biology to clinical applications. Physiol. Res. 60, 1525.

Rapport, M. M., Green, A. A., and Page, I. H. (1948). Serum vasoconstrictor, serotonin; isolation and characterization. J. Biol. Chem. 176, 1243-1251.

Renner, U., Zeug, A., Woehler, A., Niebert, M., Dityatev, A., Dityateva, G., et al. (2012). Heterodimerization of serotonin receptors 5-HT1A and 5-HT7 differentially regulates receptor signalling and trafficking. J. Cell Sci. 125, 2486-2499. doi: 10.1242/jcs.101337

Roberts, A. J., and Hedlund, P. B. (2012). The 5-HT(7) receptor in learning and memory. Hippocampus 22, 762-771. doi: 10.1002/hipo.20938

Roberts, A. J., Krucker, T., Levy, C. L., Slanina, K. A., Sutcliffe, J. G., and Hedlund, P. B. (2004). Mice lacking 5-HT receptors show specific impairments in contextual learning. Eur. J. Neurosci. 19, 1913-1922. doi: 10.1111/j.1460-9568.2004. 03288.x

Rojas, P. S., Neira, D., Muñoz, M., Lavandero, S., and Fiedler, J. L. (2014). Serotonin (5-HT) regulates neurite outgrowth through 5-HT1A and 5-HT7 receptors in cultured hippocampal neurons. J. Neurosci. Res. 92, 1000-1009. doi: 10.1002/jnr. 23390

Romano, E., Ruocco, L. A., Nativio, P., Lacivita, E., Ajmone-Cat, M. A., Boatto, G., et al. (2014). Modulatory effects following subchronic stimulation of brain 5-HT7-R system in mice and rats. Rev. Neurosci. 25, 383-400. doi: 10. 1515/revneuro-2014-0007

Ruat, M., Traiffort, E., Leurs, R., Tardivel-Lacombe, J., Diaz, J., Arrang, J. M., et al. (1993). Molecular cloning, characterization and localization of a high-affinity serotonin receptor (5-HT7) activating cAMP formation. Proc. Natl. Acad. Sci. U S A 90, 8547-8551. doi: 10.1073/pnas.90.18.8547

Ruocco, L. A., Romano, E., Treno, C., Lacivita, E., Arra, C., Gironi-Carnevale, U. A., et al. (2014b). Emotional and risk seeking behavior after prepuberal subchronic or adult acute stimulation of 5-HT7-Rs in naples high excitability rats. Synapse 68, 159-167. doi: 10.1002/syn.21724

Ruocco, L. A., Treno, C., Gironi Carnevale, U. A., Arra, C., Boatto, G., Nieddu, M., et al. (2014a). Prepuberal stimulation of 5-HT7-R by LP-211 in a rat model of hyper-activity and attention-deficit: permanent effects on attention, brain amino acids and synaptic markers in the fronto-striatal interface. PLoS One 9:e83003. doi: 10.1371/journal.pone.0083003

Sala, C., and Segal, M. (2014). Dendritic spines: the locus of structural and functional plasticity. Physiol. Rev. 94, 141-188. doi: 10.1152/physrev.00012.2013

Savelieva, K. V., Zhao, S., Pogorelov, V. M., Rajan, I., Yang, Q., Cullinan, E., et al. (2008). Genetic disruption of both tryptophan hydroxylase genes dramatically reduces serotonin and affects behavior in models sensitive to antidepressants. PLoS One 3:e3301. doi: 10.1371/journal.pone.0003301

Speranza, L., Chambery, A., Di Domenico, M., Crispino, M., Severino, V., Volpicelli, F., et al. (2013). The serotonin receptor 7 promotes neurite outgrowth via ERK and Cdk5 signaling pathways. Neuropharmacology 67, 155-167. doi: 10. 1016/j.neuropharm.2012.10.026

Tajiri, M., Hayata-Takano, A., Seiriki, K., Ogata, K., Hazama, K., Shintani, N., et al. (2012). Serotonin 5-HT(7) receptor blockade reverses behavioral abnormalities in PACAP-deficient mice and receptor activation promotes neurite extension in primary embryonic hippocampal neurons: therapeutic implications for psychiatric disorders. J. Mol. Neurosci. 48, 473-481. doi: 10.1007/s12031-0129861-y 
Vasefi, M. S., Kruk, J. S., Heikkila, J. J., and Beazely, M. A. (2013a). 5Hydroxytryptamine type 7 receptor neuroprotection against NMDA-induced excitotoxicity is PDGF $\beta$ receptor dependent. J. Neurochem. 125, 26-36. doi: 10. $1111 /$ jnc. 12157

Vasefi, M. S., Yang, K., Li, J., Kruk, J. S., Heikkila, J. J., Jackson, M. F., et al. (2013b). Acute 5-HT7 receptor activation increases NMDA-evoked currents and differentially alters NMDA receptor subunit phosphorylation and trafficking in hippocampal neurons. Mol. Brain 6:24. doi: 10.1186/1756-6606-6-24

Velasquez, J. C., Goeden, N., and Bonnin, A. (2013). Placental serotonin: implications for the developmental effects of SSRIs and maternal depression. Front. Cell Neurosci. 7:47. doi: 10.3389/fncel.2013.00047

Vitalis, T., Ansorge, M. S., and Dayer, A. G. (2013). Serotonin homeostasis and serotonin receptors as actors of cortical construction: special attention to the 5-HT3A and 5-HT6 receptor subtypes. Front. Cell Neurosci. 7:93. doi: 10. 3389/fncel.2013.00093
Conflict of Interest Statement: The authors declare that the research was conducted in the absence of any commercial or financial relationships that could be construed as a potential conflict of interest.

Received: 22 July 2014; accepted: 27 August 2014; published online: 12 September 2014. Citation: Volpicelli F, Speranza L, di Porzio U, Crispino $M$ and Perrone-Capano $C$ (2014) The serotonin receptor 7 and the structural plasticity of brain circuits. Front. Behav. Neurosci. 8:318. doi: 10.3389/fnbeh.2014.00318

This article was submitted to the journal Frontiers in Behavioral Neuroscience.

Copyright (๑) 2014 Volpicelli, Speranza, di Porzio, Crispino and Perrone-Capano. This is an open-access article distributed under the terms of the Creative Commons Attribution License (CC BY). The use, distribution or reproduction in other forums is permitted, provided the original author(s) or licensor are credited and that the original publication in this journal is cited, in accordance with accepted academic practice. No use, distribution or reproduction is permitted which does not comply with these terms. 